\title{
C-Reactive Protein Gene Polymorphisms in Disease Susceptibility and Clinical Manifestations of Korean Systemic Lupus Erythematosus
}

\author{
HYOUN-AH KIM, HYE-YOUNG CHUN, SEUNG-HYUN KIM, HAE-SIM PARK, and CHANG-HEE SUH
}

\begin{abstract}
Objective. C-reactive protein (CRP) is a sensitive marker of inflammation. It is hypothesized that polymorphism of CRP gene contributes to susceptibility to systemic lupus erythematosus (SLE). We tested this hypothesis by identifying CRP gene polymorphisms in Korean patients with SLE.

Methods. Approximately $1.5 \mathrm{~kb}$ of CRP promoter region was screened for single nucleotide polymorphism (SNP) using direct sequencing and 3 SNP in CRP exons by restriction fragment length polymorphism. The basal levels of CRP were measured by immunoturbidimetry. The effect of -390 $\mathrm{C}>\mathrm{A}$ or $\mathrm{T}$ polymorphism on the promoter activity was analyzed by luciferase reporter assay in Hep3B cells.

Results. Allele frequency at polymorphisms within CRP promoter and exon in our Korean patients with SLE differed from that of Caucasians. The A allele was a major allele at position 2043 in Korean SLE patients, whereas G is a major allele in Caucasian SLE. Our SLE patients had minor allele in the -390 polymorphism more frequently versus controls $(\mathrm{p}=0.033)$. CRP 1185 polymorphism was associated with thrombocytopenia $(\mathrm{p}=0.043)$. The basal levels of CRP were significantly higher in individuals who had minor allele in -390 and 2043 polymorphisms $(\mathrm{p}=0.03 \cdot \mathrm{p}=$ 0.024 , respectively). Promoter-reporter construct carrying the $-390 \mathrm{~A}$ or $\mathrm{T}$ allele displayed significantly higher promoter activity than that with the $-390 \mathrm{C}$ allele $(\mathrm{p}<0.001)$.

Conclusion. CRP gene -390 polymorphism plays a role in disease susceptibility of SLE through regulation of serum CRP level. Our results suggest that elevated basal CRP level may be important in the pathogenesis of SLE, even though CRP responsiveness to noninfectious inflammation of SLE is decreased. (First Release Sept 15 2009; J Rheumatol 2009;36:2238-43; doi:10.3899/jrheum.090243)
\end{abstract}

Key Indexing Terms:

SYSTEMIC LUPUS ERYTHEMATOSUS

SINGLE NUCLEOTIDE POLYMORPHISM

\section{C-REACTIVE PROTEIN PROMOTER ACTIVITY}

Systemic lupus erythematosus (SLE) is a systemic autoimmune disease characterized by highly variable clinical features. Although the exact pathogenesis of SLE remains elusive, extremely complicated and multifactorial interactions among various genetic and environmental factors are thought to contribute to the development of the disease ${ }^{1}$. Many genetic association studies have been performed among human populations with SLE, and various genes encoding proteins with regulatory or adaptive functions in the immune system have been considered as candidates ${ }^{2,3}$.

Several different approaches with variable validation

From the Department of Allergy and Rheumatology, Ajou University School of Medicine, Suwon, Korea.

Supported by a 2004 grant from the Department of Medical Sciences, Graduate School, Ajou University; and a grant from the Korean Health 21 $R \& D$ project, Ministry of Health \& Welfare, ROK. (A050571).

H.A. Kim, MD; H.Y. Chun, MS; S.H. Kim, PhD; H.S. Park, MD, PhD; C.H. Suh, MD, PhD.

Address correspondence to Dr. C-H. Suh, Department of Allergy and Rheumatology, Ajou University School of Medicine, Woncheon-dong San 5, Youngtong-gu, Suwon, Korea 443-721.E-mail: chsuh@ajou.ac.kr Accepted for publication May 19, 2009. have been used for genome wide scanning to identify novel susceptibility loci for SLE, and 13 major cytogenetic locations show significant evidence of linkage to SLE. Among the identified linkages are 8 SLE susceptibility regions that have also been replicated independently using lupus phenotypes only. They include 1q23, 1q41, 2q37, 4p16, 6p21, 11p13, 12q24, and 16q13. Within 1q23.2, C-reactive protein (CRP) gene has been considered as a lupus candidate gene $^{2,4,5}$.

$\mathrm{CRP}$ is one of the major plasma proteins that increase in concentration during the acute phase. It recognizes pathogens and mediates their elimination by recruiting the complement system and phagocytic cells. Further, CRP appears to play a role in the clearance of apoptotic and necrotic cells, an effect that likely contributes to homeostasis and systemic autoimmune diseases ${ }^{6,7}$. The single CRP gene consists of 2 exons that have disproportionately long 3 ' untranslated regions (3'-UTR $)^{8}$, suggesting a possible regulatory role.

It is of interest to note that CRP may exert an ameliorative effect on murine models of $\mathrm{SLE}^{9,10}$. Also, in SLE patients, there is little or no increase of CRP level with flare- 
up of the disease. When elevated CRP levels are detected, they are indicative of an intercurrent infection rather than of active lupus ${ }^{11-19}$. These findings raise the possibility that decreased amounts of CRP may contribute to the pathogenesis of SLE. Recently, some studies showed association between CRP gene polymorphism and SLE ${ }^{13-17}$. However, the SNP found to be associated with SLE has no known functional role in CRP production, and it remains unknown if any promoter SNP are associated with the disease.

Therefore, we attempted to identify single nucleotide polymorphisms (SNP) in the CRP promoter region, determine their frequency in Korean populations, and elucidate their significance in susceptibility and clinical phenotype of SLE. Also, we evaluated whether CRP gene polymorphisms are associated with serum levels of CRP.

\section{MATERIALS AND METHODS}

Subjects. One hundred forty-eight patients, diagnosed with SLE, were enrolled. All met the revised criteria of the American College of Rheumatology (ACR) for classification of $\mathrm{SLE}^{18}$. As well, 137 normal control subjects (NC) were recruited. Whole blood samples were collected for the genetic study, and serum samples were collected for the measurement of CRP.

Medical history, clinical symptoms, physical examination, and laboratory results were registered in a database from the onset of disease until admission to the study through review of medical records. All subjects gave their informed consent and the study was approved by the Institutional Review Board.

Preparation of genomic DNA and identification of single nucleotide polymorphism. Genomic DNA was prepared from whole blood samples using the G-DEXTM genomic DNA Extraction Kit for blood (iNtRON Biotechnology, Sungnam, Korea) according to the manufacturer's protocol.

Primers designated for amplification and sequencing analyses were based on the sequences of CRP in NCBI. Polymerase chain reaction (PCR) was performed with these primers using genomic DNA from SLE patients $(\mathrm{n}=50)$ and NC $(\mathrm{n}=50)$. Collected DNA was sequenced (Bionics, Seoul, Korea), and MultAlin interface page (INRA, Toulouse, France) was used for comparing the sequence of each subject with SNP information of CRP obtained from the SNP database in NCBI.

Genotyping. The SNP identified in the CRP promoter region were additionally genotyped using direct sequencing for SLE patients $(n=98)$ and NC $(n=87)$. Also 3 SNP in CRP exon region that have been reported in European populations were genotyped by restriction fragment length polymorphism (RFLP) ${ }^{16}$. Polymorphisms identified by PCR-RFLP were confirmed by sequencing.

Serum CRP level. The serum CRP levels were immunoturbidimetrically measured using AU640e Chemistry Immunoanalyser (Olympus, Southall, UK). Serum samples were collected at clinic visits in SLE patients without infection and flareup.

Effect of -390 C $>A$ or $T$ polymorphism on promoter activity. We prepared 577-bp fragment of the promoter of human CRP by PCR amplification using either $-390 \mathrm{C}$ homozygote, $-390 \mathrm{~A}$ homozygote, or $-390 \mathrm{~T}$ homozygote human genomic DNA as a template. Each of the PCR products were gel purified with an agarose-gel purification kit (iNtRON Biotechnology), and ligased into TA vector (Invitrogen, Carlsbad, CA, USA). All constructs were verified by direct sequencing. Plasmid DNA were prepared from these constructs.

Hep3B cells (human liver hepatoma cell line) were cultured with RPMI 1640 (Invitrogen, Grand Island, $\mathrm{NY}, \mathrm{USA}$ ) at $37^{\circ} \mathrm{C}$ in a $5 \% \mathrm{CO}_{2}$ incubator. Hep3B cells were transfected by using FuGENE6 (Roche, Mannheim, Germany) according to the manufacturer's instructions.
Luciferase reporter assays were performed following the protocol supplied by the manufacturer (Promega). Thus cells were lysated with $100 \mu \mathrm{l}$ of reporter lysis buffer per well. Twenty microliters from $100 \mu \mathrm{l}$ of the cell lysate were assayed for luciferase activity using a luciferase assay kit and a luminometer TD20/20 (Turner BioSystems, Sunnyvale, CA, USA). Assays were conducted in triplicate, and experiments were repeated at least 3 times.

Statistical analysis. The genotype frequency at each SNP was examined for significant departure from Hardy-Weinberg equilibrium by using a chi-square test. Three logistic regression models (codominant, dominant, recessive) were used to analyze SNP after controlling for age and gender as covariables. Haplotypes of CRP gene were analyzed using Haploview version 4.0 based on the EM algorithm. CRP basal levels according to the SNP genotype in SLE were assessed using logistic regression analysis to control for disease duration and Bonferroni adjustment for multiple comparisons, and CRP value is shown as median (25th percentile, 75th percentile). Differences of promoter activity assay among each group were examined by using chi-square test. Differences in the frequency of the phenotypic characteristics within SLE patients were assessed using logistic regression analysis to control for age and gender as covariables. A p value $\leq 0.05$ was regarded as significant. All statistical analyses were performed using SPSS software (version 12.0; SPSS Inc, Chicago, IL, USA).

\section{RESULTS}

Clinical characteristics of the study subjects. The mean age of SLE patients was $35.7 \pm 12.4$ years and $89.9 \%$ were women. In NC, mean age was $25.7 \pm 4.1$ years and $70.1 \%$ were women. There were differences in age and gender between both groups, so the data were analyzed with logistic regression analysis to control for age and sex. Clinical features of SLE patients are as follows with decreasing frequency: ANA positivity (98.6\%), arthritis (73\%), hypocomplementemia $(72.3 \%)$, anti-dsDNA positivity $(68.2 \%)$, oral ulcer (53.4\%), leukopenia (50\%), anticardiolipin antibody positivity (44.6\%), malar rash $(37.2 \%)$, nephritis $(32.4 \%)$, photosensitivity (25\%), thrombocytopenia (22.3\%), serositis (18.2\%), lupus anticoagulant positivity (14.2\%), and anti-Sm antibody positivity (7.4\%).

SNP discovery of promoter region of CRP gene. We sequenced a $1.5 \mathrm{~kb}$ of CRP promoter region from 50 SLE patients and $50 \mathrm{NC}$ to identify polymorphism sites. Three SNP of CRP promoter region were identified; $-861 \mathrm{~T}>\mathrm{C}$, $-821 \mathrm{~A}>\mathrm{G}$, and $-390 \mathrm{C}>\mathrm{T}$ or $\mathrm{A}$ (Figure 1).

Genotyping frequencies of CRP gene. The distribution of genotype frequencies for all polymorphisms was consistent with Hardy-Weinberg equilibrium in SLE and NC ( $p>$ 0.05). The genotype frequency of each SNP of CRP promoter region in Korean SLE is presented in Table 1. The frequency of the genotype that contained the $-390 \mathrm{~A}$ or T allele was significantly higher in SLE compared with NC ( $p=$ 0.033 for the recessive model). There were no significant differences in allele and genotype frequencies in SNP of CRP exon region between SLE and NC (data not shown).

Linkage disequilibrium between SNP, and locus by locus was examined. Two genetic polymorphisms of the CRP gene, $839 \mathrm{G}>\mathrm{C}$ and $1185 \mathrm{C}>\mathrm{T}$, were in linkage disequilibrium (1D' $1=1$ and $\left.r^{2}=0.12\right)$, and 7 common haplotypes, 


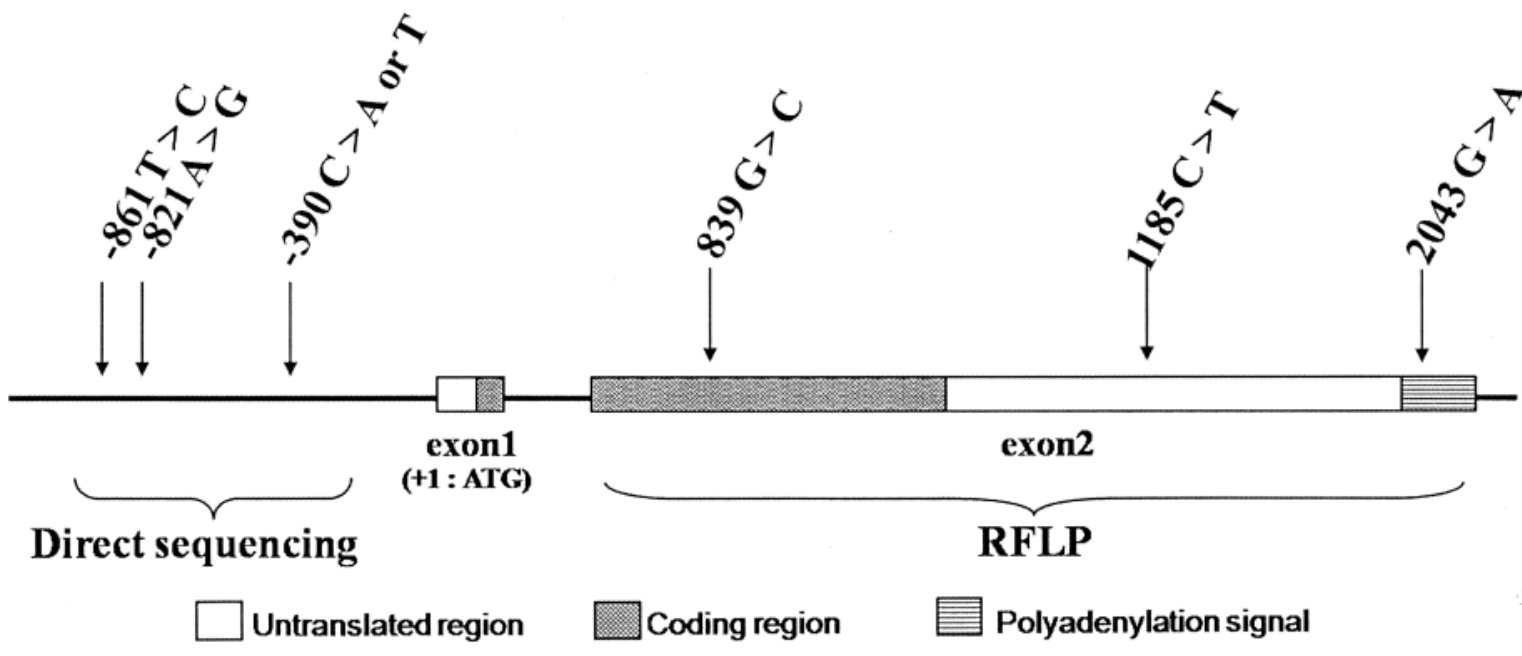

Figure 1. Schematic representation of the C-reactive protein (CRP) gene. CRP consists of 2 exons separated by a single intron. Filled boxes denote translated regions and open boxes untranslated regions. Arrows mark the locations of single nucleotide polymorphisms (SNP) within CRP locus.

Table 1. The genotype and allele frequencies of polymorphisms in the promoter region of CRP gene.

\begin{tabular}{|c|c|c|c|c|}
\hline & & $\begin{array}{c}\text { SLE, } \\
\mathrm{n}=148(\%)\end{array}$ & $\begin{array}{c}\mathrm{NC} \\
\mathrm{n}=137(\%)\end{array}$ & $\mathrm{p}$ \\
\hline \multirow[t]{4}{*}{$-861 \mathrm{~T}>\mathrm{C}$} & $\mathrm{TT}$ & $105(70.9)$ & $108(78.8)$ & cod: NS \\
\hline & $\mathrm{CT}$ & $41(27.7)$ & $29(21.2)$ & dom: NS \\
\hline & $\mathrm{CC}$ & $2(1.4)$ & $0(0.0)$ & rec: NS \\
\hline & q. & 0.152 & 0.106 & al: NS \\
\hline \multirow[t]{4}{*}{$-821 \mathrm{~A}>\mathrm{G}$} & AA & $122(82.4)$ & $101(73.7)$ & cod: NS \\
\hline & $\mathrm{AG}$ & $23(15.5)$ & $32(23.4)$ & dom: NS \\
\hline & GG & $3(2.0)$ & $4(2.9)$ & rec: 0.079 \\
\hline & $\mathrm{q}$. & 0.098 & 0.146 & al: NS \\
\hline-390 & $\mathrm{CC}$ & $78(52.7)$ & $96(70.1)$ & cod: 0.051 \\
\hline \multirow[t]{6}{*}{$\mathrm{C}>\mathrm{A}$ or $\mathrm{T}$} & $\mathrm{AC}$ & $41(27.7)$ & $26(19.0)$ & dom: NS \\
\hline & $\mathrm{CT}$ & $27(18.2)$ & $12(8.8)$ & rec: 0.033 \\
\hline & AA & $1(0.7)$ & $0(0.0)$ & \\
\hline & AT & $0(0.0)$ & $3(2.2)$ & \\
\hline & $\mathrm{TT}$ & $1(0.7)$ & $0(0.0)$ & \\
\hline & q. & 0.243 & 0.161 & al: 0.071 \\
\hline
\end{tabular}

Each p value was calculated with co-dominant (cod), dominant (dom), and recessive models (rec). al: $\mathrm{p}$ value of each allele frequency. Logistic regression analysis was applied to control for age and gender as covariables. SLE: systemic lupus erythematosus; NC: normal control; NS: not significant.

ht1[TACGCA], ht2[TGCGCG], ht3[CAAGCG], ht4[TATGTG], ht5[TACCCA], ht6[TACGCG], and ht7[TACGTG], were constructed utilizing the EM algorithm. There was no difference in the frequency of each haplotype between SLE and NC (data not shown).

CRP basal levels according to SNP genotype and haplotype in SLE. We evaluated associations between SNP genotype and CRP basal levels. Table 2 shows that SLE patients who
Table 2. C-reactive protein (CRP) basal levels according to the SNP genotype in SLE. CRP values are median (25th percentile, 75 th percentile).

\begin{tabular}{|c|c|c|c|}
\hline Genotype & CRP levels (mg/l) & $\mathrm{p}^{\mathrm{a}}$ & $\mathrm{p}^{\mathrm{b}}$ \\
\hline \multicolumn{4}{|l|}{$-861 \mathrm{~T}>\mathrm{C}$} \\
\hline $\mathrm{TT}(\mathrm{n}=105)$ & $0.2(0.0,0.4)$ & & \\
\hline $\mathrm{CT}, \mathrm{CC}(\mathrm{n}=43)$ & $0.4(0.2,0.5)$ & NS & NS \\
\hline \multicolumn{4}{|l|}{$-821 \mathrm{~A}>\mathrm{G}$} \\
\hline $\mathrm{AA}(\mathrm{n}=122)$ & $0.2(0.0,0.4)$ & & \\
\hline AG, GG $(n=26)$ & $0.4(0.3,0.6)$ & 0.042 & NS \\
\hline \multicolumn{4}{|l|}{$-390 \mathrm{C}>\mathrm{A}$ or $\mathrm{T}$} \\
\hline $\mathrm{CC}(\mathrm{n}=78)$ & $0.2(0.0,0.4)$ & & \\
\hline $\mathrm{CT}, \mathrm{AC}, \mathrm{AA}, \mathrm{AT}$, or TT $(\mathrm{n}=70)$ & $0.3(0.2,0.5)$ & 0.023 & 0.03 \\
\hline \multicolumn{4}{|c|}{$839 \mathrm{G}>\mathrm{C}$} \\
\hline $\mathrm{GG}(\mathrm{n}=136)$ & $0.3(0.1,0.5)$ & & \\
\hline CG, CC $(n=12)$ & $0.1(0.0,0.3)$ & NS & NS \\
\hline \multicolumn{4}{|l|}{$1185 \mathrm{C}>\mathrm{T}$} \\
\hline $\mathrm{CC}(\mathrm{n}=122)$ & $0.2(0.0,0.5)$ & & \\
\hline $\mathrm{CT}, \mathrm{TT}(\mathrm{n}=26)$ & $0.3(0.2,0.5)$ & NS & NS \\
\hline \multicolumn{4}{|l|}{$2043 \mathrm{~A}>\mathrm{G}$} \\
\hline $\mathrm{AA}(\mathrm{n}=60)$ & $0.2(0.0,0.4)$ & & \\
\hline $\mathrm{AG}, \mathrm{GG}(\mathrm{n}=88)$ & $0.3(0.2,0.5)$ & 0.05 & 0.024 \\
\hline
\end{tabular}

${ }^{a}$ Logistic regression analysis to control for disease duration as a covariable. ${ }^{b}$ Bonferroni adjustment for multiple comparisons. NS: not significant.

carried the $-390 \mathrm{~A}$ or $\mathrm{T}$ allele had higher basal levels of CRP than those who had the homozygous CC genotype ( $\mathrm{p}=$ 0.03). The basal CRP levels were higher in SLE patients who carried the $2043 \mathrm{G}$ allele versus those who had the homozygous AA genotype $(p=0.024)$. Effect of $2043 \mathrm{~A}>\mathrm{G}$ polymorphism on CRP expression has been reported by Russell, et $a l^{16}$. Also, the basal level of CRP was lower in SLE patients who had haplotype ht1[TACGCA] and higher 
in SLE patients who had haplotype ht4[TATGTG]; however, significance was lost after Bonferroni adjustment (Table 3). The data are consistent with the basal CRP level according to genotype.

Therefore, we assayed the promoter activity of $-390 \mathrm{C}>$ A or T polymorphism of CRP gene, which showed a significant difference of allelic frequency in SLE versus NC, and we evaluated the association of promoter activity and basal CRP levels in SLE patients.

Effect of $-390 C>A$ or T polymorphism on the transcription activity of human CRP promoter. To examine whether the

Table 3. C-reactive protein (CRP) basal levels according to the haplotype of CRP gene. CRP values are median (25th percentile, 75 th percentile)

\begin{tabular}{lcccc}
\hline Haplotype & & CRP Levels mg/l & $\mathrm{p}^{\mathrm{a}}$ & $\mathrm{p}^{\mathrm{b}}$ \\
\hline Ht1[TACGCA] & TACGCA $(\mathrm{n}=172)$ & $0.2(0.0,0.4)$ & & \\
& $-(\mathrm{n}=124)^{*}$ & $0.3(0.1,0.5)$ & 0.006 & $\mathrm{NS}$ \\
Ht2[TGCGCG] & TGCGCG $(\mathrm{n}=29)$ & $0.4(0.3,0.5)$ & & \\
& $-(\mathrm{n}=267)^{*}$ & $0.3(0.2,1.0)$ & NS & NS \\
Ht3[CAAGCG] & CAAGCG $(\mathrm{n}=43)$ & $0.4(0.2,0.5)$ & & \\
& $-(\mathrm{n}=253)^{*}$ & $0.2(0.0,0.4)$ & NS & NS \\
Ht4[TATGTG] & TATGTG $(\mathrm{n}=23)$ & $0.3(0.2,0.5)$ & & \\
& $-(\mathrm{n}=273)^{*}$ & $0.2(0.0,0.5)$ & 0.035 & NS \\
Ht5[TACCCA] & TACCCA $(\mathrm{n}=12)$ & $0.1(0.0,0.3)$ & & \\
& $-(\mathrm{n}=284)^{*}$ & $0.3(0.1,0.5)$ & NS & NS \\
Ht6[TACGCG] & TACGCG $(\mathrm{n}=6)$ & $0.8(0.2,1.2)$ & & \\
& $-(\mathrm{n}=290)^{*}$ & $0.3(0.0,0.5)$ & NS & NS \\
Ht7[TACGTG] & TACGTG $(\mathrm{n}=4)$ & $0.2(0.0,0.4)$ & & \\
& $-(\mathrm{n}=292)^{*}$ & $0.3(0.1,0.5)$ & NS & NS \\
& & & & \\
& & &
\end{tabular}

${ }^{a}$ Logistic regression analysis to control for disease duration as a covariable. ${ }^{b}$ Bonferroni adjustment for multiple comparisons. NS: not significant. * SLE patients who did not have haplotype.
-390 C>A or T polymorphism was associated with altered promoter activity, we employed a luciferase reporter assay to compare the reporter activity of plasmids that contained $-390 \mathrm{C},-390 \mathrm{~A}$ or $-390 \mathrm{~T}$ in the CRP promoter. Figure 2 shows that constructs containing $-390 \mathrm{~A}$ and $-390 \mathrm{~T}$ exhibited significantly greater luciferase activity than the constructs containing $-390 \mathrm{C}(\mathrm{p}<0.001)$.

Associations between SLE phenotype and SNP. We evaluated a possible association between the CRP polymorphisms and clinical characteristics of SLE. As seen in Table 4, the thrombocytopenia rate was more common in patients who carried the $1185 \mathrm{~T}$ allele than in those who had the homozygous $1185 \mathrm{CC}$ genotype ( $\mathrm{p}=0.043)$.

As for associations between SLE phenotypes and 7 common haplotypes, the frequency of hypocomplementemia was significantly higher in patients who had haplotype ht1[TACGCA], whereas it was significantly lower in haplotype ht2[TGCGCG] (Table 4).

\section{DISCUSSION}

We investigated whether a polymorphism at the CRP promoter region might contribute to genetic susceptibility to human SLE. In fact, several studies have found that a polymorphism in the CRP gene is associated with an increased risk of developing SLE, and clinical and experimental evidence suggests a possible participatory role of CRP in pathogenesis $2,4,13-17,19$. Two studies have found evidence of association between CRP variants and SLE or lupus nephritis in Caucasians ${ }^{14,16}$. One study showed that a CRP promoter variant, -707, was associated with the SLE phenotype in African Americans and Caucasians ${ }^{13}$. A recent study in a British family-based cohort found that 5 SNP $(-861,-390$,

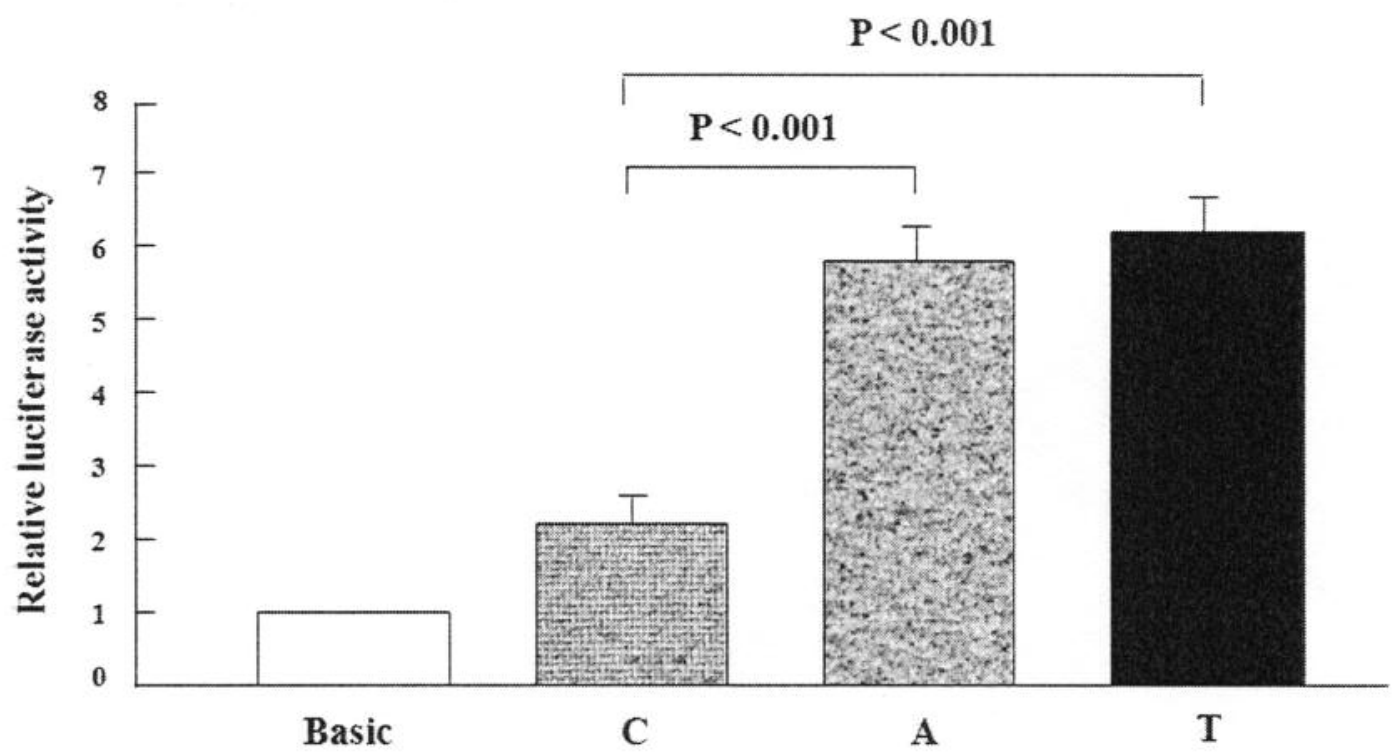

Figure 2. Effect of $-390 \mathrm{C}>\mathrm{A}$ or $\mathrm{T}$ polymorphism on the transcription activity of human CRP promoter. A reporter assay was performed in Hep3B cells transfected with luciferase reporter constructs. The relative luciferase activity is represented as the ratio to the activity of pGL3-Basic. Each experiment was conducted in triplicate, and the results are expressed as mean + SEM for 3 independent experiments. $p$ value was determined by paired $t$ test.

Personal non-commercial use only. The Journal of Rheumatology Copyright @ $@ 2009$. All rights reserved. 
Table 4. Association of clinical manifestations and genotype/haplotype of SNP in CRP gene.

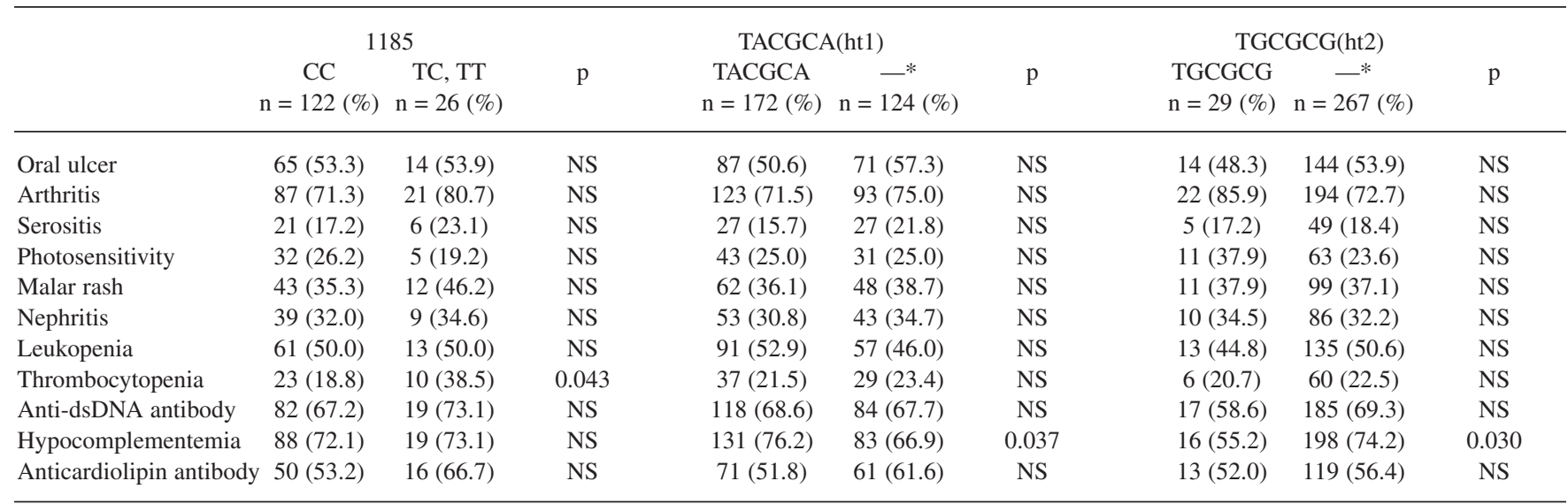

Logistic regression analysis was applied to control for age and gender as covariables. NS $=$ not significant; ACA $=$ anticardiolipin antibody. * Did not have haplotype.

90, 838, 2043) were not associated with SLE risk individually, but there was an association with the 5 SNP haplotypes ${ }^{17}$. In our present study, we investigated SNP in the CRP promoter region and found $3 \mathrm{SNP}(-861 \mathrm{~T}>\mathrm{C},-821$ $\mathrm{A}>\mathrm{G},-390 \mathrm{C}>\mathrm{A}$ or $\mathrm{T}$ ) in Koreans. Further, we found that the rare allele frequency of $-390 \mathrm{C}>\mathrm{A}$ or $\mathrm{T}$ polymorphism was significantly higher in SLE than NC. Also, the allele frequencies for $6 \mathrm{CRP}$ polymorphisms in Koreans were remarkably different versus Caucasians: The A allele was a major allele in Korean patients at position 2043, whereas G allele was reported as a major allele in Caucasian and African Americans ${ }^{13,15,16}$. These results clearly indicate genetic variation among different ethnic groups.

We also examined whether these polymorphisms had any effect on serum CRP levels, and found that basal levels of CRP were significantly higher in individuals who had minor allele in $-390 \mathrm{C}>\mathrm{A}$ or $\mathrm{T}$ and $2043 \mathrm{~A}>\mathrm{G}$ polymorphisms than in those who had the major homozygous genotype, even after conservative Bonferroni adjustment for multiple comparisons $(\mathrm{p}=0.03,0.024$, respectively). These results are comparable with the previous reports in Caucasians ${ }^{16,17,20-22}$. Further, we extended this finding to basal CRP level according to haplotype, and found that the basal level of CRP was lower in haplotype ht1[TACGCA] containing major alleles of CRP -390 and 2043, while it was higher in haplotype ht4[TATGTG] containing minor alleles of CRP -390 and 2043, although the significance disappeared with Bonferroni adjustment.

We thought that the $-390 \mathrm{C}>\mathrm{A}$ or $\mathrm{T}$ polymorphism would be associated with altered promoter activity. Using a luciferase reporter assay, we observed that constructs containing $-390 \mathrm{~A}$ and $-390 \mathrm{~T}$ exhibited significantly greater luciferase activity than constructs that contained -390C.

The influence of genetic polymorphisms in CRP on clinical manifestations of SLE was examined. Thrombocytopenia developed significantly more in SLE patients who had minor allele in $1185 \mathrm{~T}>\mathrm{C}$ polymorphisms than those who had major homozygous genotype. Although the pathogenesis of lupus thrombocytopenia has not yet been clarified, one possible explanation of the association between $1185 \mathrm{C}$ allele and thrombocytopenia in our study could be a reduced capacity for antiinflammatory effects of CRP in patients with the variant allele C. A recent report suggested that CRP generates suppressive macrophages through Fc $\gamma \mathrm{RI}$ to decrease platelet clearance in a model of immune thrombocytopenic purpura ${ }^{23}$. The frequency of hypocomplementemia was significantly higher in haplotype ht1[TACGCA] and lower in haplotype ht2[TGCGCG]. These results suggest that the combination of $-821 \quad A>G$ and $2043 A>G$ polymorphism may be important for hypocomplementemia. However, we could not replicate the association between CRP 2043 polymorphism and lupus nephritis ${ }^{14}$.

It is of an interest to note that our results were in contrast with previous data that showed an ameliorative effect of CRP on SLE. In a previous genetic study, a polymorphism in the human CRP gene, $2043 \mathrm{~A}>\mathrm{G}$, which results in a lower basal level of CRP, has been associated with an increased risk of developing $\mathrm{SLE}^{16}$. Using a sensitive method, however, some studies observed that most SLE patients have elevated CRP levels during the evolution of the disease process, irrespective of concomitant active infection ${ }^{24,25}$. One recent study assessed the relationship among high-sensitivity CRP (hsCRP), clinical features, autoantibody and organ damage, and found that hsCRP was associated with a broad range of clinical features and organ damage in $\mathrm{SLE}^{26}$.

Our present data showed that $-390 \mathrm{C}>\mathrm{A}$ or $\mathrm{T}$ polymorphism, which was associated with elevated basal CRP, was associated with susceptibility to SLE. This SNP is associated with higher promoter activity based on functional studies in transfected cells. Further studies on how elevated basal CRP levels contribute to resting status without flareup of disease are needed.

Our study also has some limitations. The study was performed in a single population of patients without replication, 
and the studied population was relatively small. Also, there are possible biases of using young people as controls, who may develop lupus later; however, this is rather unlikely due to the low incidence rate.

It is not clear how elevation of basal CRP level in complex disorders such as SLE is a risk factor of chronic inflammation or a contributing factor to the pathogenesis of the disease. If elevation of baseline CRP level has a role in the pathogenesis of SLE, the alleles related to elevation of baseline CRP could also be a contributing factor to disease pathogenesis. These data appear to be useful in understanding basal CRP expression and its relation to SLE.

In conclusion, our results suggest that $-390 \mathrm{C}>\mathrm{A}$ or $\mathrm{T}$ polymorphism within CRP promoter region may be involved in regulation of CRP expression and susceptibility to SLE in Koreans. In addition, multiple polymorphisms with CRP gene may be involved in clinical manifestation.

\section{REFERENCES}

1. D'Cruz DP, Khamashta MA, Hughes GR. Systemic lupus erythematosus. Lancet 2007;369:587-96.

2. Croker JA, Kimberly RP. Genetics of susceptibility and severity in systemic lupus erythematosus. Curr Opin Rheumatol 2005;17:529-37.

3. Nath SK, Kilpatrick J, Harley JB. Genetics of human systemic lupus erythematosus: the emerging picture. Curr Opin Immunol 2004;16:794-800.

4. Tsao BP. Update on human systemic lupus erythematosus genetics. Curr Opin Rheumatol 2004;16:513-21.

5. Moser KL, Neas BR, Salmon JE, Yu H, Gray-McGuire C, Asundi $\mathrm{N}$, et al. Genome scan of human systemic lupus erythematosus: evidence for linkage on chromosome 1q in African-American pedigrees. Proc Natl Acad Sci U S A 1998;95:14869-74.

6. Volanakis JE. Human C-reactive protein: expression, structure, and function. Mol Immunol 2001;38:189-97.

7. Rosen A, Casciola-Rosen L. Clearing the way to mechanisms of autoimmunity. Nat Med 2001;7:664-5.

8. Woo P, Korenberg JR, Whitehead AS. Characterization of genomic and complementary DNA sequence of human C-reactive protein, and comparison with the complementary DNA sequence of serum amyloid P component. J Biol Chem 1985;260:13384-8.

9. Szalai AJ, Weaver CT, McCrory MA, van Ginkel FW, Reiman RM, Kearney JF, et al. Delayed lupus onset in (NZB x NZW)F1 mice expressing a human C-reactive protein transgene. Arthritis Rheum 2003;48:1602-11.

10. Du Clos TW, Zlock LT, Hicks PS, Mold C. Decreased autoantibody levels and enhanced survival of (NZB x NZW) F1 mice treated with C-reactive protein. Clin Immunol Immunopathol 1994;70:22-7.

11. Suh CH, Jeong YS, Park HC, Lee CH, Lee J, Song CH, et al. Risk factors for infection and role of C-reactive protein in Korean patients with systemic lupus erythematosus. Clin Exp Rheumatol 2001;19:191-4.

12. Suh CH, Chun HY, Ye YM, Park HS. Unresponsiveness of C-reactive protein in the non-infectious inflammation of systemic lupus erythematosus is associated with interleukin 6. Clin Immunol 2006;119:291-6.
13. Edberg JC, Wu J, Langefeld CD, Brown EE, Marion MC, McGwin $\mathrm{G}$, Jr., et al. Genetic variation in the CRP promoter: association with systemic lupus erythematosus. Hum Mol Genet 2008; 17:1147-55.

14. Jonsen A, Gunnarsson I, Gullstrand B, Svenungsson E, Bengtsson AA, Nived O, et al. Association between SLE nephritis and polymorphic variants of the CRP and FcgammaRIIIa genes. Rheumatology (Oxford) 2007;46:1417-21.

15. Rhodes B, Meek J, Whittaker JC, Vyse TJ. Quantification of the genetic component of basal C-reactive protein expression in SLE nuclear families. Ann Hum Genet 2008;72:611-20.

16. Russell AI, Cunninghame Graham DS, Shepherd C, Roberton CA, Whittaker J, Meeks J, et al. Polymorphism at the C-reactive protein locus influences gene expression and predisposes to systemic lupus erythematosus. Hum Mol Genet 2004;13:137-47.

17. Shih PB, Manzi S, Shaw P, Kenney M, Kao AH, Bontempo F, et al. Genetic variation in C-reactive protein (CRP) gene may be associated with risk of systemic lupus erythematosus and CRP concentrations. J Rheumatol 2008;35:2171-8.

18. Tan EM, Cohen AS, Fries JF, Masi AT, McShane DJ, Rothfield NF, et al. The 1982 revised criteria for the classification of systemic lupus erythematosus. Arthritis Rheum 1982;25:1271-7.

19. Linares LF, Gomez-Reino JJ, Carreira PE, Morillas L, Ibero I. C-reactive protein (CRP) levels in systemic lupus erythematosus (SLE). Clin Rheumatol 1986;5:66-9.

20. Kovacs A, Green F, Hansson LO, Lundman P, Samnegard A, Boquist $\mathrm{S}$, et al. A novel common single nucleotide polymorphism in the promoter region of the $\mathrm{C}$-reactive protein gene associated with the plasma concentration of $\mathrm{C}$-reactive protein. Atherosclerosis 2005;178:193-8.

21. Szalai AJ, Wu J, Lange EM, McCrory MA, Langefeld CD, Williams A, et al. Single-nucleotide polymorphisms in the C-reactive protein (CRP) gene promoter that affect transcription factor binding, alter transcriptional activity, and associate with differences in baseline serum CRP level. J Mol Med 2005;83:440-7.

22. Carlson CS, Aldred SF, Lee PK, Tracy RP, Schwartz SM, Rieder M, et al. Polymorphisms within the C-reactive protein (CRP) promoter region are associated with plasma CRP levels. Am J Hum Genet 2005;77:64-77.

23. Marjon KD, Marnell LL, Mold C, Du Clos TW. Macrophages activated by C-reactive protein through Fc gamma RI transfer suppression of immune thrombocytopenia. J Immunol 2009;182:1397-403.

24. Williams RC Jr, Harmon ME, Burlingame R, Du Clos TW. Studies of serum C-reactive protein in systemic lupus erythematosus. J Rheumatol 2005;32:454-61.

25. al-Mekaimi A, Malaviya AN, Serebour F, Umamaheswaran I, Kumar R, al-Saeid K, et al. Serological characteristics of systemic lupus erythematosus from a hospital-based rheumatology clinic in Kuwait. Lupus 1997;6:668-74.

26. Lee SS, Singh S, Link K, Petri M. High-sensitivity C-reactive protein as an associate of clinical subsets and organ damage in systemic lupus erythematosus. Semin Arthritis Rheum 2008;38:41-54. 